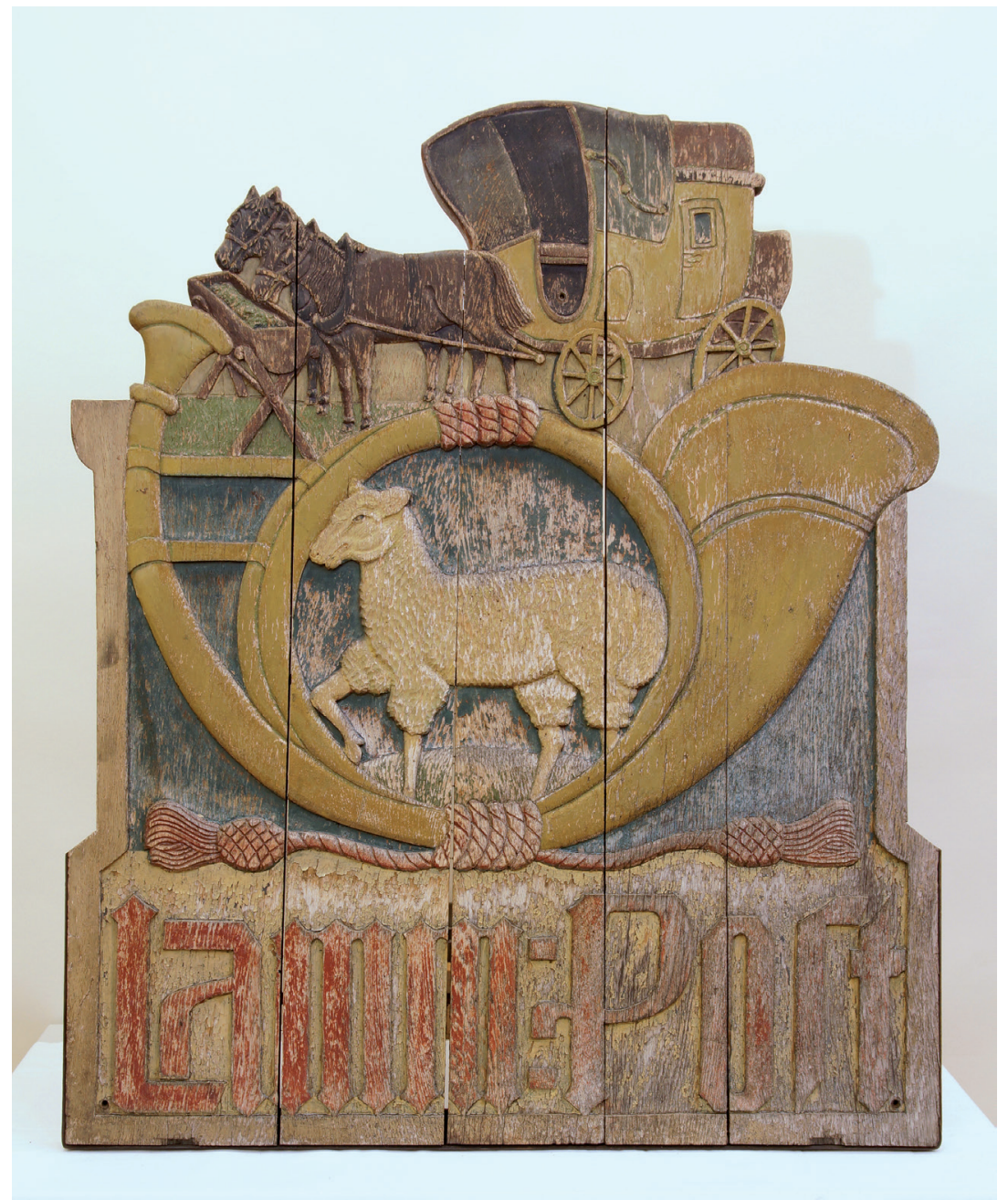

Abb. 1 Das Schild vor der Konservierung (Aufnahme: Volker Immel, Ilshofen) (Inv. Nr. 2013/0004)

\title{
Ein Firmenschild des einstigen Hotels „Lamm-Post“ in Schwäbisch Hall
}

Anstehende Geburtstage, vor allem wenn es sich um runde handelt, veranlassen in der Regel nicht nur Familienangehörige, sondern auch Freunde und Bekannte der oder des zu Feiernden, sich Gedanken über ein passendes Geburtstagsgeschenk zu machen. Aber je älter eine Jubilarin oder ein Jubilar wird, desto schwieriger ist es, ein geeignetes Präsent zu finden, denn für die meisten Men- 


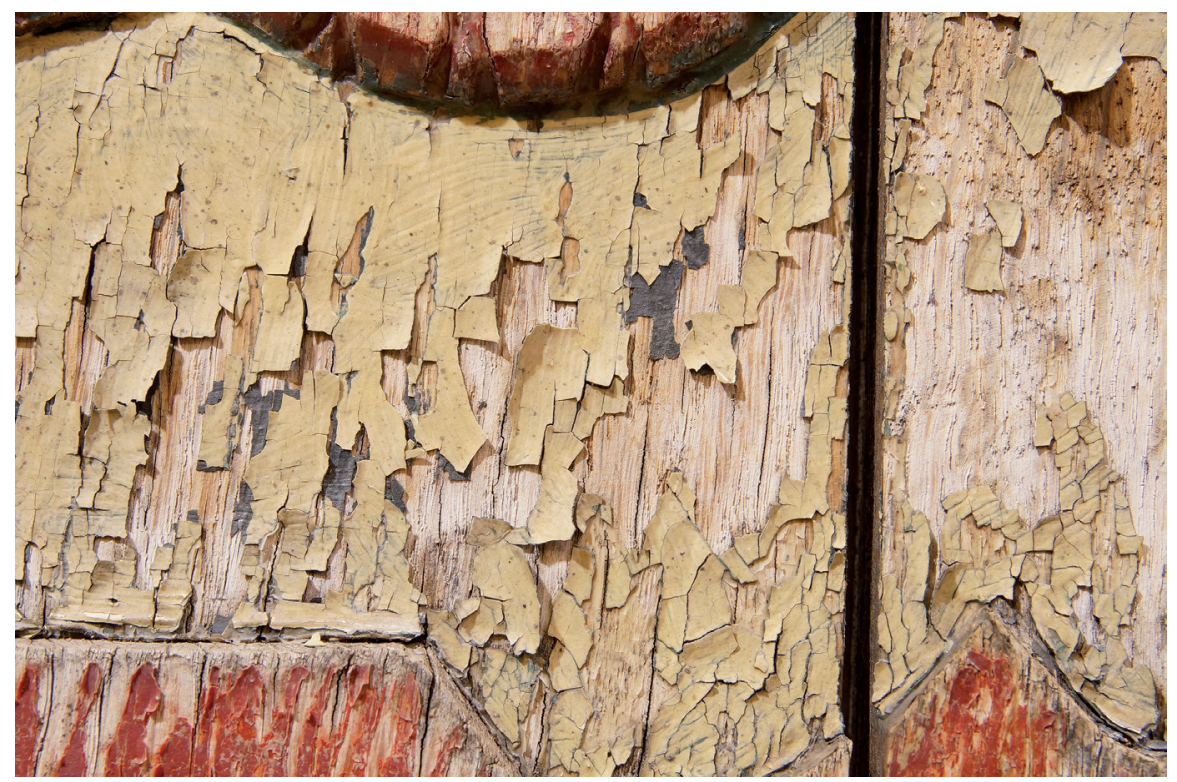

Abb. 2 Detailaufnahme der sich lösenden Farbschichten (Aufnahme: Volker Immel, Ilshofen)

schen verlieren im vorgerückten Alter materielle Dinge mehr und mehr an Bedeutung. Gesundheit und persönliches Wohlergehen werden zu den primären Werten im Leben. Außerdem kommen bei derlei Überlegungen auch viele zu dem Schluss, dass sie im Grunde eigentlich wunschlos glücklich sind.

Diese Situation stellte sich vor kurzem auch einer Gruppe von Freunden des Vorsitzenden des Historischen Vereins für Württembergisch Franken, als Dr. Ernst Breit seinen 70. Geburtstag beging. Die damals im Verein geführte Diskussion über den Ankauf eines historischen Hausschildes vom ehemaligen Hotel „Lamm-Post“ in Schwäbisch Hall brachte Frau Bünstorf und die Familien Lenner, Heinz, Panter und Beutter auf eine nicht alltägliche Idee: Sie erwarben das Schild und schenkten es dem Jubilar, wohl wissend, dass das Objekt nach der dringend notwendigen Konservierung durch einen Restaurator als so genanntes Patengeschenk der Sammlung des Historischen Vereins einverleibt und im Hällisch-Fränkischen Museum gezeigt werden wird ${ }^{1}$. Der Vereinsvorsitzende ist ein großer Befürworter dieser Art von Stiftungen, die in Zeiten knapper Kassen helfen, wichtiges Kulturgut für die Region zu bewahren.

Das Hotel „Lamm-Post“ war einer der renommierten Beherbergungs- und Gastronomiebetriebe in Schwäbisch Hall. Seit dem Großen Stadtbrand von 1728

1 Der Historische Verein für Württembergisch Franken ist Mitträger des Hällisch-Fänkischen Museums. 
hatte es seinen Standort an der nordöstlichen Ecke des Milchmarktes (angrenzend an die nach dem Brand neu angelegte Neue Straße). Heue steht auf dem Grundstück (Neue Straße 7) das „Glashaus“, in dem die Haller Stadtbibliothek untergebracht ist. Das barocke Hotelgebäude war kurz vor Ende des Zweiten Weltkrieges zerstört worden. Von Brandbomben getroffen, brannte es - wie auch das Haller Rathaus - am 16./17 April 1945 aus.

Eugen Gutöhrlein, der in den 1930er Jahren die Immobilie von Georg Hahn übernommen hatte, plante den Wiederaufbau des Gebäudes. Nachdem es darüber zwischen ihm und der Haller Stadtverwaltung zu keinem Konsens kam, verkaufte er das Ruinengrundstück 1950 an die Landeszentralbank und zog nach Neckargemünd (Rhein-Neckar-Kreis) bei Heidelberg, wo er wieder eine Gastwirtschaft eröffnete.

Das hölzerne Hotelschild nahm Gutöhrlein - vielleicht als Erinnerung an seine Zeit in Schwäbisch Hall - mit nach Neckargemünd und brachte es dort an seinem Haus an. Als er den Betrieb der Gastwirtschaft aufgab, kaufte ihm ein befreundeter Kollege und Antiquitätensammler aus der Nachbarschaft das Schild ab. Dieser, nun selbst ins Rentenalter gekommen und mit der Auflösung seines Weinstubeninventars und seiner Sammlung beschäftigt, wollte durch die Kontaktaufnahme mit dem Hällisch-Fränkischen Museum beziehungsweise dem Historischen Verein das Schild wieder an seinen Entstehungsort zurückführen. Das 124 x 104,5 x 4,5 cm große, farbig gefasste Schild ist aus fünf Eichenbohlen zusammengefügt (rechts und links begleitet je ein breiteres Brett die drei schmäleren in der Mitte). Auf der Rückseite werden diese von zwei quer aufgenagelten Eisenschienen und am unteren Rand durch ein weiteres Bandeisen zusammengehalten. Die Schrift und die Figuren sind in flacher Relieftechnik gearbeitet, der obere Rand ist entlang der Figurenkonturen ausgesägt.

Die Sockelzone trägt in steilen Lettern den Schriftzug „Lamm:Post“. Darüber nimmt ein Horn mit zwei Windungen und einer ausladenden Stürze die an beiden Seiten etwas eingezogene Schildfläche ein. Das Mundrohr des Instrumentes verbinden zwei Stege mit einer der beiden Windungen, die oben und unten von einer Kordel zusammengehalten werden. Die untere Umwicklung endet in zwei dicken Quasten. In dem runden Feld zwischen den Windungsbögen steht ein weißes Lamm mit leicht erhobenem rechtem Vorderbein. Über dem Horn schließt ein vor einer gefüllten Futterkrippe stehendes Gespann mit zwei Pferden und einem geschlossenen Reisewagen das Hausschild ab.

Die Entstehungszeit wie auch der ursprüngliche Verwendungsort des Schildes sind ungewiss. Stilistisch verweisen die in der Arbeit erkennbaren Anklänge an den Jugendstil diese in die Zeit um 1900/1910. Den drei vorhandenen alten Bohrlöchern nach zu schließen, hatte sie ihren Platz an einer Wand. Auf alten Ansichten $^{2}$ ist jedoch an den Schauseiten des Hotels (Milchmarkt/Neue Straße)

2 Postkarten aus den 1930er Jahren und ein Druck von 1880 (Häuserlexikon des Stadtarchivs Schwäbisch Hall unter www.schwaebischhall.de). 


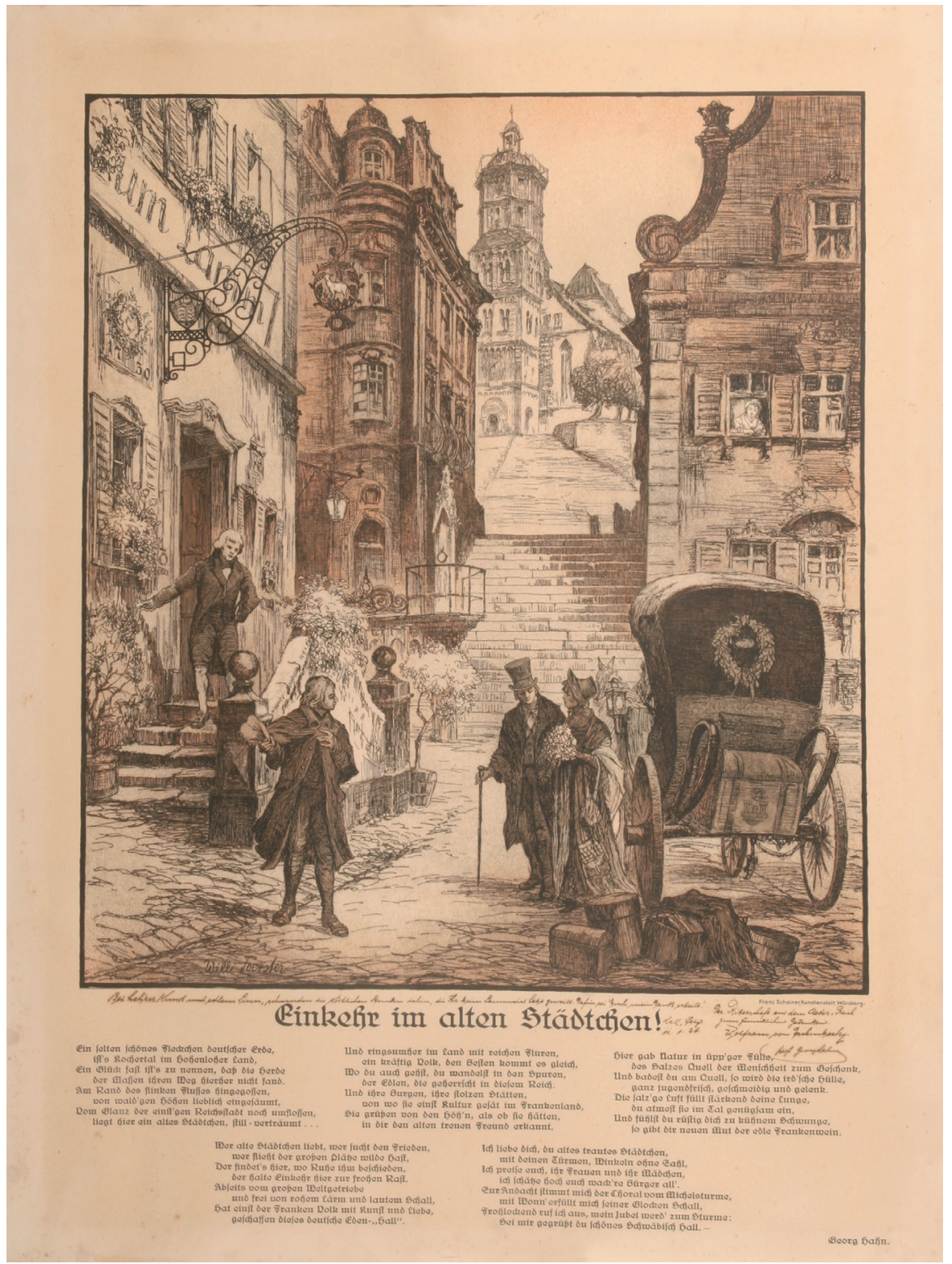

Abb. 3 Plakat des Hotels „Lamm-Post“. Farbdruck der Kunstanstalt Franz Schreiner, Würzburg, um 1925. Die Vorlage für die Graphik schuf der Künstler Willi Foerster (1892-1965) aus Rothenburg ob der Tauber. Sie zeigt im Hintergrund die Haller Michaelskirche mit der großen Freitreppe. Davor ist die breite Treppengasse zwischen dem Rathaus und dem Widmanhaus 
ein solches Schild nicht zu erkennen. Zur Neuen Straße hin hatte das Hotel einen schmiedeeisernen Ausleger (vgl. Abb. 3). Vielleicht diente das hölzerne Relief dazu, um an einem Hinter- oder Hofeingang beziehungsweise an einem Remisengebäude oder einer Stallung auf die Unterstellmöglichkeiten des Hotels „Lamm-Post“ hinzuweisen. Für eine solche Verwendung spricht auch das am oberen Rand dargestellte Gespann: Es befindet sich in Wartestellung. Die Kutsche ist leer - ohne Kutscher, ohne Reisende und ohne Gepäck, und die Pferde können vor der Weiterfahrt Futter aus der vor ihnen stehenden Krippe aufnehmen.

Herta Beutter

wiedergegeben. Den Vordergrund gestaltete Foerster collagenartig, indem er in diesen den Pranger, den Eingang des Hotels „Lamm-Post“ samt dem schmiedeeisernen Ausleger und ein Gästepaar mit seinem Gepäck vor einer Equipage mit dem Rothenburger Stadtwappen hineinkomponierte. Unter dem Bild rühmt ein von Georg Hahn, dem damaligen Besitzer des Hotels, verfasstes pathetisches Gedicht die Schönheiten Schwäbisch Halls. Das im Hällisch-Fränkischen Museum verwahrte Exemplar trägt zudem die folgende handschriftliche Widmung: „Bei hehrer Kunst und edlem Sinn, schwanden die Köstlichen Stunden dahin, die Ihr beim Lammwirt habt geweilt. Dafür sei Euch mein Dank erteilt! / Hall, W[ür]tt[em]b[er]g. / 11. 1. [19]26. / Der Ritterschaft aus dem Aeter-Reich / zum freundlichen Gedenken. / Wolfram von Eschenbach. / [...] Georg Hahn. (Aufnahme: Margit Kern, Schwäbisch Hall)

(Inv. Nr. 2000/0045) 